\title{
BMJ Open Did psychosocial status, sociodemographics and smoking status affect non-attendance in control participants in the Danish Lung Cancer Screening Trial? A nested observational study
}

Jessica Malmqvist (D) , ${ }^{1,2}$ Volkert Siersma (D) , ${ }^{1}$ Hanne Thorsen, ${ }^{1}$ Bruno Heleno, ${ }^{1,3}$ Jakob Fraes Rasmussen, ${ }^{1}$ John Brodersen (D) ${ }^{1,2}$

To cite: Malmqvist J, Siersma $\mathrm{V}$, Thorsen $\mathrm{H}$, et al. Did psychosocial status, sociodemographics and smoking status affect non-attendance in control participants in the Danish Lung Cancer Screening Trial? A nested observational study. BMJ Open 2020;10:e030871. doi:10.1136/ bmjopen-2019-030871

- Prepublication history for this paper is available online. To view these files, please visit the journal online (http://dx.doi. org/10.1136/bmjopen-2019030871).

Received 11 April 2019 Revised 25 November 2019 Accepted 28 January 2020
Check for updates

(C) Author(s) (or their employer(s)) 2020. Re-use permitted under CC BY-NC. No commercial re-use. See rights and permissions. Published by BMJ.

For numbered affiliations see end of article.

Correspondence to Dr Jessica Malmqvist; jessica.malmqvist@sund.ku.dk

\section{ABSTRACT}

Objectives We investigated if psychosocial status, sociodemographics and smoking status affected nonattendance in the control group in the randomised Danish Lung Cancer Screening Trial (DLCST).

Design and setting This study was an observational study nested in the DLCST. Due to large non-attendance in the control group in the second screening round we made an additional effort to collect questionnaire data from non-attenders in this group in the third screening round. We used a condition-specific questionnaire to assess psychosocial status. We analysed the differences in psychosocial status in the third and preceding rounds between non-attenders and attenders in the control group in multivariable linear regression models adjusted for sociodemographics and smoking status reported at baseline. Differences in sociodemographics and smoking status were analysed with $\chi^{2}$ tests (categorical variables) and t-tests (continuous variables).

Primary outcome measure Primary outcome was psychosocial status.

Participants All control persons participating in the third screening round in the DLCST were included.

Results Non-attenders in the third round had significantly worse psychosocial status than attenders in the scales: 'behaviour' 0.77 (99\% Cl 0.18 to 1.36), 'self-blame' 0.59 (99\% Cl 0.14 to 1.04), 'focus on airway symptoms' 0.22 (99\% Cl 0.08 to 0.36), 'stigmatisation' 0.51 (99\% Cl 0.16 to 0.86$)$, 'introvert' 0.56 (99\% $\mathrm{Cl} 0.23$ to 0.89$)$ and 'harms of smoking' $0.35(99 \% \mathrm{Cl} 0.11$ to 0.59$)$. Moreover, non-attenders had worse scores than attendees in the preceding screening rounds. Non-attenders also reported worse sociodemographics at baseline.

Conclusions Non-attenders had a significantly worse psychosocial status and worse sociodemographics compared with attenders. The results of our study contribute with evidence of non-response and attrition driven by psychosocial status, which in turn may be influenced by the screening intervention itself. This can be used to adjust cancer screening trial results for bias due to differential non-attendance.

\section{Strengths and limitations of this study}

- Use of a condition-specific questionnaire with adequate psychometric properties ensured valid measures.

- Patient-reported data on non-respondents gave valuable empirical insight in drivers for non-attendance.

- Testing a previously hypothesised model for nonattendance empirically is another strength of the study.

- No comparison between non-attenders in the intervention and the control group was performed.

- No longer term follow-up on non-attenders was performed.

Trial registration number Clinicaltrials.gov Protocol Registration System (NCT00496977).

\section{INTRODUCTION}

Non-attendance may affect trial results and introduce bias in randomised controlled trials (RCTs). ${ }^{2}$ Non-attendance reduces the power of the trial and, if non-attendance differs between the randomised groups, conventional effect estimates can be biased. ${ }^{2}$ While we cannot change the loss of power, we may remove bias due to differential nonattendance if we know and have measured the factors that cause this non-attendance. ${ }^{3}$ For some outcome measures, such as disease incidence or mortality, non-attendance can be partially addressed if data can be obtained from national electronic registers. However, non-attendance will be larger for outcome measures that depend on direct data collection such as clinical measurements and patient-reported outcome measures (PROMs). Moreover, the factors driving 


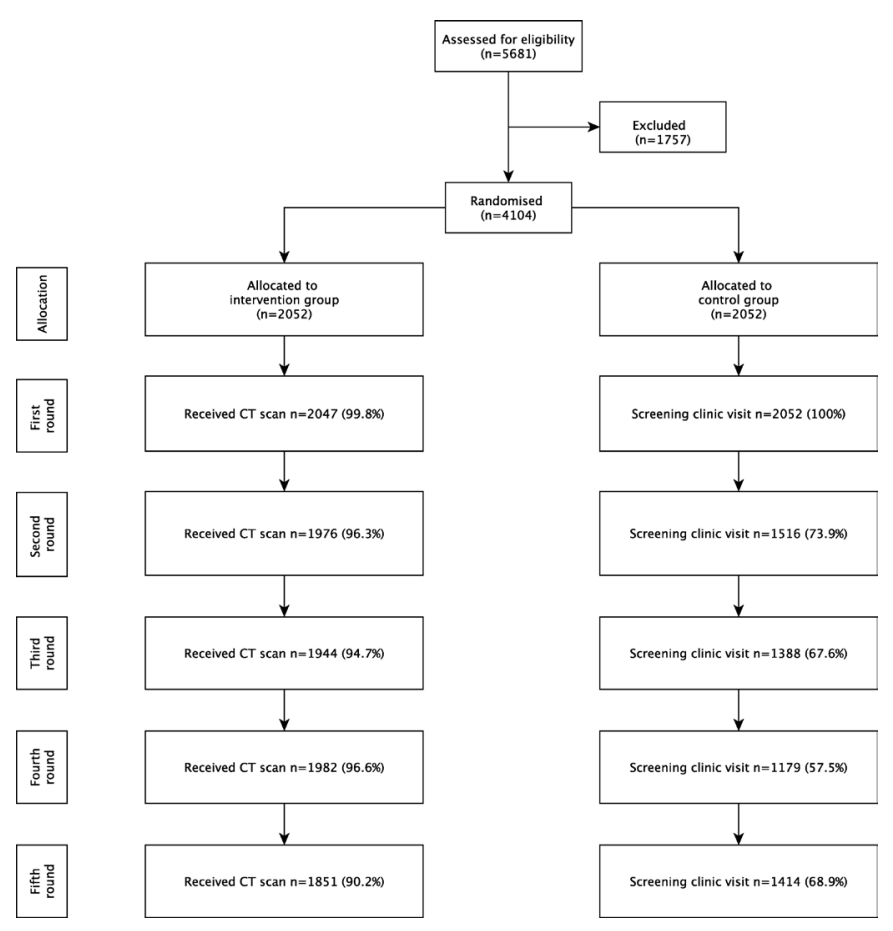

Figure 1 Flowchart, the Danish Lung Cancer Screening Trial.

non-attendance for these measures may be very heterogeneous and may also be driven by the experiences of the trial participants in the trial process.

The problems with differential non-attendance may be aggravated in trials assessing psychosocial consequences of cancer screening as well as other interventions where it is impossible to blind participants to allocation. Notably, a control group not offered screening may be less inclined to return questionnaires enquiring into their experiences with a potentially beneficial intervention they did not receive. However, the psychosocial dimensions of nonattendance and potential consequences of these in lung cancer screening trials are only partially researched. ${ }^{4-7}$ Since cancer screening trials are investigating potentially life-threatening diseases there may be emotional drivers of non-attendance, not typical for trials in general. Hence, it is of interest to know which factors drive non-attendance in PROMs in cancer screening trials as these data are to be collected in these trials and then used in adjusting for differential non-attendance.

The Danish Lung Cancer Screening Trial (DLCST) was an RCT including five annual screening rounds of low-dose chest CT plus clinical examinations in the intervention group compared with annual clinical examinations only in the control group. ${ }^{8}$ Furthermore, all the participants were asked to complete a condition-specific questionnaire, measuring psychosocial consequences of lung cancer screening at these annual clinical assessments. ${ }^{9}$ The results showed that people experienced negative psychosocial consequences merely by participating in the trial, and that negative consequences were higher for participants allocated to the control group. ${ }^{70}$ A large number of control persons did not attend the second annual examination $(\mathrm{n}=513,26.1 \%)$, while the non-attendance rate in the intervention group was low $(\mathrm{n}=71,3.5 \%)$ (figure 1$)$. To adjust for this differential non-attendance, inverse probability weighting was used. ${ }^{7}$ In this method, the observed outcomes are weighted with the inverse of the probability of being non missing. ${ }^{3}$ We hypothesised that these probabilities were adequately estimated from sociodemographic profile including smoking status, randomisation group and psychosocial status in previous rounds. ${ }^{71-13}$

If these hypotheses were confirmed, then these factors would explain the witnessed difference in attendance between the trial groups and could be used to render them comparable. Analysed without such adjustments the assessment of the trial groups, and thereby the means of the scores from the responses to the questionnaire from the remaining trial participants would no longer be comparable. ${ }^{14}$ Hence, the assessment of psychosocial harms of lung cancer screening could be biased.

Therefore, the overall aim of this study was to empirically assess whether control participants who did not attend the annual clinical examination had different psychosocial profiles compared with control participants who attended the annual clinical examination.

\section{MATERIALS AND METHODS}

\section{Study design and population}

The design and study population of DLCST have been described in detail previously. ${ }^{78}$ Briefly, the DLCST was an RCT, conducted at the Copenhagen University Hospital Gentofte in Denmark from October 2004 to March 2010. Heavy current and former smokers (at least 20 pack-years), aged 50-70 years old, were randomised to either five rounds of screening with low-dose CT scans including clinical examinations $(n=2052)$ or five clinical examinations only $(\mathrm{n}=2052)$. In the enrolment visit, participants provided sociodemographic data, lifestyle and health information (including smoking status), completed a questionnaire on their psychosocial status and underwent spirometry. Participants randomised to screening also had a low-dose chest CT scan within 1 month of randomisation. In the following screening rounds, participants in the screened and control groups were invited to a visit in the screening clinic where lung function tests were performed, and questionnaires concerning health, lifestyle, smoking habits and psychosocial status were completed and lung function tests were performed. Participants randomised to screening also received a low-dose chest CT scan.

This study is an observational study nested in the DLCST. During the second screening round, the steering committee noted that a large number of control participants did not attend the screening clinic visit when compared with the number of screened participants. Thus, the committee decided to make additional efforts to collect questionnaire data for non-attenders in the control group in the third screening round to perform posthoc analyses on whether psychosocial status was an influencing factor (figure 2). 


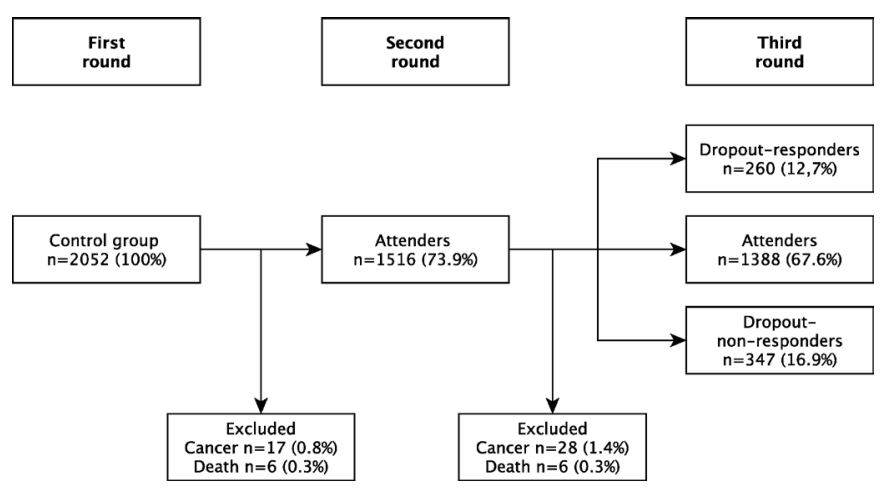

Figure 2 Flowchart, present study.

During the third round, participants in the control group who did not attend the annual examination were contacted by phone, and part 1 of the questionnaire was sent with a postage paid envelope to those who gave their oral consent. The data were used to supplement the data collected on site at the screening clinic. ${ }^{7}$ This yielded three groups within the control group, denoting the extent of response to the clinical examination and the questionnaire defined as:

1. Attenders: participants who attended the third screening round.

2. Non-attenders:

a. Respondents: participants who did not attend the annual examination but completed and returned the Consequences in Screening in Lung Cancer (COS-LC) after the phone interview.

b. Non-respondents: participants who did not attend the annual examination and did not complete the COS-LC.

Primary outcome was psychosocial status measured with the COS-LC questionnaire. ${ }^{9}$ Part 1 of COS-LC comprised nine scales measuring various aspects of consequences of screening; a second part of COS-LC addressed the screening outcome and was therefore not applicable to the present analysis. Moreover, the primary part of COS-LC included four core scales: 'anxiety', 'behaviour', 'dejection' and 'sleep' that are not lung cancer specific. These scales have originally been developed from a breast cancer screening assessment instrument. ${ }^{15}$ Additionally COS-LC comprised five lung cancer-specific scales: 'selfblame', 'focus on airway symptoms', 'stigmatisation', 'introvert' and 'harm of smoking', which were developed from focus groups and other screening assessment instruments during the first DLCST screening round. ${ }^{915}$ Therefore, only the core scales were used in the first round, while in the following four screening rounds, both the core scales and the lung cancer-specific scales were used to assess psychosocial status. ${ }^{9}$

\section{Statistics}

Covariates

Sociodemographic characteristics were defined by: social class (I highest social class to V lowest social class), school and vocational education (from 9 years of elementary school to a university education), employment status, living alone, smoking status (current or former smoker), smoking history (pack-years), motivation for smoking cessation (from very strong to no wish to quit) and Charlson Comorbidity Index (CCI). Furthermore, we adjusted for region of residence (Denmark is divided into five health administrative regions).

\section{Statistical analyses}

We performed three different analyses:

1. Analyses of differences in psychosocial status in the third round between attenders and non-attenders respondents.

2. Analyses of differences in psychosocial status in the second round between attenders, non-attenders respondents and non-attenders non-respondents.

3. Analyses of differences in psychosocial status in the first round, between attenders, non-attenders respondents and non-attenders non-respondents.

Covariates at the first screening round were compared between attenders and non-attenders by $\chi^{2}$ tests (categorical characteristics) and t-tests (continuous characteristics). Analyses of psychosocial status at various points in the follow-up were performed in linear regression models both unadjusted and in multivariable models adjusted for sex, age, region of residence, social class, living alone, smoking status, pack-years, motivation for smoking cessation and CCI. To adjust for multiple testing, we used the Benjamini-Hochberg procedure and the False Discovery Rate (FDR) was set to 5\%. ${ }^{16}$ All analyses were performed with SAS V.9.4 (SAS Institute).

\section{Patient and public involvement}

Patients and public were not involved in the design of the study.

\section{RESULTS}

The inclusion process and participation rate of the DLCST are illustrated in figure 1. The participation rate in the control group fell from $73.9 \%$ in the second round to $57.5 \%$ in the fourth round. The participation rate increased in the fifth, final, round $(68.9 \%)$.

Figure 2 depicts the inclusion process of the present study and showed a dropout rate of $29.6 \%(n=607)$ in the third screening round with a higher distribution of nonattenders non-respondents $(16.9 \% \quad \mathrm{n}=347)$ compared with non-attenders respondents $(12.7 \% \mathrm{n}=260)$.

In the first screening round we compared differences in sociodemographic characteristics in the two overarching groups (attenders, non-attenders) (table 1).

There was a significant difference between the study groups for social class with more non-attenders in the lowest social class (V) and a greater number of attenders in the highest social classes (I-II).

Moreover, non-attenders had a significantly higher CCI score indicating that they had more severe or a greater number of co-occurring conditions than attenders. They were also to a greater extent living alone. Furthermore, 
Open access

Table 1 Sociodemographics

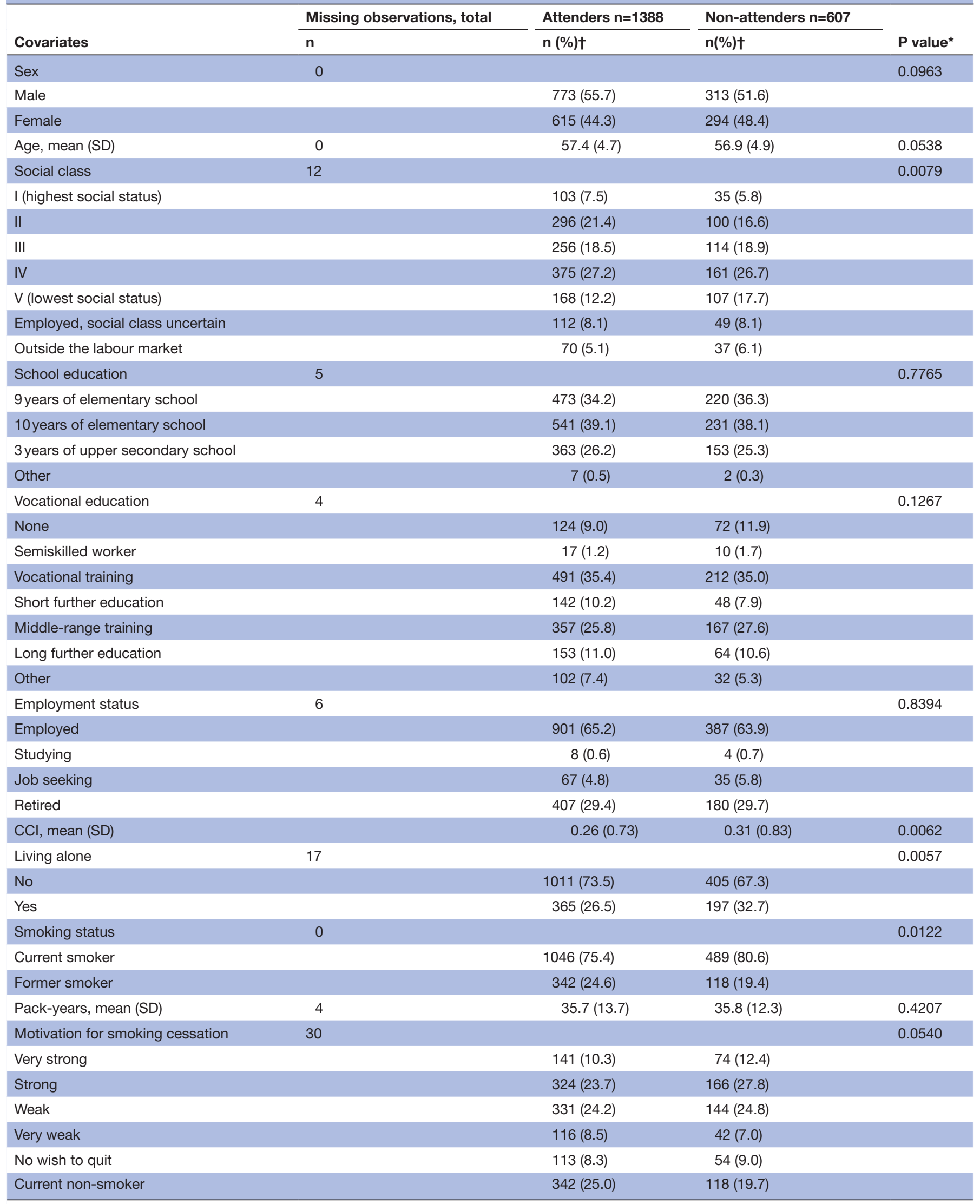

*Benjamini-Hochberg rejects all $p$ values above 0.0321 to control the FDR at 0.05 .

$\dagger$ Except when indicated in the leftmost column that the mean and SD are listed.

$\mathrm{CCl}$, Charlson Comorbidity Index; FDR, False Discovery Rate. 
Table 2 Differences in psychosocial status in the third screening round

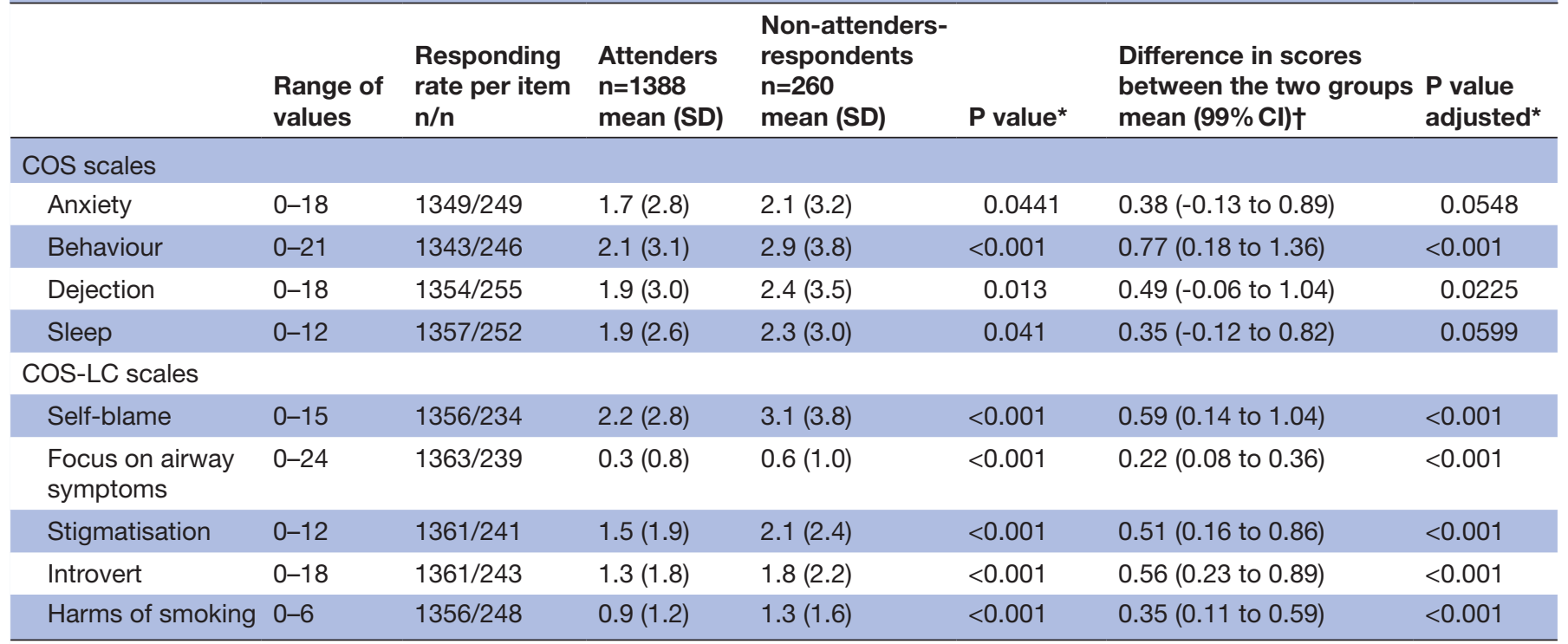

${ }^{*}$ Benjamini-Hochberg rejects all $p$ values above 0.0321 to control the FDR at 0.05 .

†A positive value of the difference indicates that the persons that were interviewed by phone and later returned COS-LC had on average higher scores, that is, more negative outcomes (eg, higher anxiety) than the persons that showed up and completed the COS-LC on site. The differences are adjusted for sex, age, region of residence, social group, living alone, smoking status, pack-years, motivation for smoking cessation and $\mathrm{CCl}$. The continuous values variables (age and pack-years) are included as a quadratic function as to allow for possible non-linear effects.

CCl, Charlson Comorbidity Index; COS, Consequences in Screening; COS-LC, Consequences in Screening in Lung Cancer; FDR, False Discovery Rate.

there were significantly more current smokers and a nonsignificant trend of a higher wish to quit smoking in the group of non-attenders compared with attenders.

The results of the third screening round are listed in table 2.

In the core questionnaire Consequences of Screening (COS), non-attenders respondents had a statistically significant higher (worse) score than attenders in the scales 'behaviour' and 'dejection'. These effects were still present when adjusting for covariates. Moreover, there was a non-significant trend of worse scores in all COS scales among non-attenders respondents. In the lung cancer-specific part of the COS-LC, non-attenders respondents had statistically significantly higher scores in all scales both crude and adjusted.

Table 3 shows differences in psychosocial status between all three subgroups in the second screening round.

Non-attenders had significantly worse crude scores compared with attenders in all the COS scales. When adjusting for covariates the difference in scores was still significant in the three scales 'anxiety', 'dejection' and 'sleep'. In the lung cancer-specific part, the crude and adjusted 'self-blame' and 'introvert' scale scores were significantly worse for non-attenders. The difference in 'stigmatisation' scale score was statistically significant in the unadjusted analyses but disappeared in the adjusted analyses.

The differences in psychosocial status in the first screening round between attenders, non-attenders respondents and non-attenders non-responders showed a statistically significant worse unadjusted score in all COS scales for the two non-attenders subgroups (table 4). That effect disappeared in all but one scale, 'anxiety' when adjusting for covariates.

\section{DISCUSSION}

The present study showed considerable non-attendance in the control group of the DLCST. Data in the control group were not missing at random. Non-attenders had less favourable baseline sociodemographic profile when compared with attenders. More importantly, individuals who did not attend their annual clinical workup had worse psychosocial status than the individuals who attended the clinic in the previous rounds. This can be used to adjust for differential non-attendance. Furthermore, these individuals also had worse psychosocial status during their missed round (assessed in the present study in the third round). This cannot be used to adjust differential non-attendance because this information is generally not available but proves the concept.

The use of a condition-specific questionnaire is a strength of the study. Previous research has demonstrated that condition-specific questionnaires are superior to generic questionnaires when measuring psychosocial consequences in cancer screening settings. ${ }^{17}$ Furthermore, we used an appropriate longitudinal design, that is, we collected data at the same time points for both attenders and non-attenders at various times in the study, as well as we measured psychosocial status in both groups at baseline. ${ }^{18}$ 
Table 3 Differences in psychosocial status in the second screening round

\begin{tabular}{|c|c|c|c|c|c|c|c|}
\hline & $\begin{array}{l}\text { Range of } \\
\text { values }\end{array}$ & $\begin{array}{l}\text { Responding } \\
\text { rate per item } \\
\mathrm{n} / \mathrm{n} / \mathrm{n}\end{array}$ & $\begin{array}{l}\text { Attenders } \\
\mathrm{n}=1388\end{array}$ & $\begin{array}{l}\text { Non-attenders } \\
\text { respondents } \\
\mathrm{n}=260\end{array}$ & $\begin{array}{l}\text { Non-attenders non- } \\
\text { respondents } n=347\end{array}$ & P value* & $\begin{array}{l}\text { P value } \\
\text { adjusted }{ }^{*}\end{array}$ \\
\hline \multicolumn{8}{|l|}{ COS scales, mean (SD) } \\
\hline Anxiety & $0-18$ & $1201 / 117 / 89$ & $1.6(2.7)$ & $2.0(3.0)$ & $2.6(3.8)$ & 0.003 & 0.018 \\
\hline Behaviour & $0-21$ & $1195 / 114 / 88$ & $1.9(2.9)$ & $2.4(3.3)$ & $2.8(4.0)$ & 0.012 & 0.071 \\
\hline Dejection & $0-18$ & $1217 / 117 / 87$ & $1.8(2.8)$ & $2.3(3.3)$ & $3.0(4.0)$ & $<0.001$ & $<0.001$ \\
\hline \multicolumn{8}{|c|}{ COS-LC scales, mean (SD) } \\
\hline Self-blame & $0-15$ & $1210 / 118 / 88$ & $1.7(2.3)$ & $2.1(2.4)$ & $2.6(3.0)$ & $<0.001$ & 0.005 \\
\hline $\begin{array}{l}\text { Focus on airway } \\
\text { symptoms }\end{array}$ & $0-24$ & $1226 / 118 / 90$ & $0.4(0.8)$ & $0.4(0.8)$ & $0.5(0.9)$ & 0.408 & 0.579 \\
\hline Stigmatisation & $0-12$ & $1225 / 121 / 90$ & $1.5(1.9)$ & $1.8(2.1)$ & $2.1(2.4)$ & 0.028 & 0.146 \\
\hline
\end{tabular}

${ }^{*}$ Benjamini-Hochberg rejects all $p$ values above 0.0321 to control the FDR at 0.05 .

†A test for differences between the three groups adjusted for sex, age, region of residence, social group, living alone, smoking status, pack-years, motivation for smoking cessation and the CCI. The continuous values variables (age and pack-years) are included as a quadratic function as to allow for possible non-linear effects.

CCI, Charlson Comorbidity Index; COS, Consequences in Screening; COS-LC, Consequences in Screening in Lung Cancer; FDR, False Discovery Rate.

A limitation of the study is that we did not collect psychosocial outcomes of non-attenders in the intervention group. This study was designed to gain knowledge of factors motivating such a large drop in participation in the control group. In hindsight, data on non-attenders in the screened group could further help us understand the reasons for differential non-response.

The distribution of psychosocial outcomes was left skewed (tables 2-4). To assure that the conclusions were not affected by this skewness, we repeated the analyses on log-transformed outcomes. The results of these sensitivity analyses reached conclusions similar to the original conclusions.
In addition to the DLCST, two other trials assessed psychosocial consequences in lung cancer screening with low-dose CT. ${ }^{19}$ Participants in the Dutch-Belgian Randomised Lung Cancer Screening trial (Dutch acronym: the NELSONstudy) were invited to complete questionnaires at baseline and at the second round of screening (2years after baseline screening). Participants in the UK Lung Cancer Screening Trial (UKLS) completed a questionnaire at baseline, 2 weeks after randomisation/CT scan and 10-29 months after baseline. Unlike the DLCST, in these two trials, the control group were not invited to an annual visit at the screening clinic. Although there were some differences in study

Table 4 Differences in psychosocial status in the first screening round

\begin{tabular}{|c|c|c|c|c|c|c|c|}
\hline & $\begin{array}{l}\text { Range of } \\
\text { values }\end{array}$ & $\begin{array}{l}\text { Responding } \\
\text { rate per item } \\
\mathrm{n} / \mathbf{n} / \mathbf{n}\end{array}$ & $\begin{array}{l}\text { Attenders } \\
n=1388 \\
\text { mean (SD) }\end{array}$ & $\begin{array}{l}\text { Non-attenders } \\
\text { respondents } \\
\mathrm{n}=260 \\
\text { mean (SD) }\end{array}$ & $\begin{array}{l}\text { Non-attenders } \\
\text { non-respondents } \\
\mathrm{n}=347 \\
\text { mean (SD) }\end{array}$ & P value* & $\begin{array}{l}\text { P value } \\
\text { adjustedt* }\end{array}$ \\
\hline \multicolumn{8}{|l|}{ COS scales } \\
\hline Anxiety & $0-18$ & $1353 / 253 / 334$ & $1.46(2.16)$ & $1.75(2.54)$ & $2.11(2.66)$ & $<0.001$ & 0.0028 \\
\hline Behaviour & $0-21$ & $1365 / 257 / 340$ & 0.75 (1.89) & $1.05(2.44)$ & $1.04(2.43)$ & 0.0134 & 0.0976 \\
\hline Dejection & $0-18$ & 1372/257/339 & $1.25(2.05)$ & $1.54(2.48)$ & $1.68(2.33)$ & 0.0018 & 0.0512 \\
\hline Sleep & $0-12$ & $1368 / 253 / 344$ & $0.62(1.64)$ & $0.86(1.98)$ & $0.90(1.86)$ & 0.0072 & 0.0530 \\
\hline
\end{tabular}

*Benjamini-Hochberg rejects all $p$ values above 0.0321 to control the FDR at 0.05

$\dagger$ The differences are adjusted for sex, age, region of residence, social group, living alone, smoking status, pack-years, motivation for smoking cessation and $\mathrm{CCl}$. The continuous values variables (age and pack-years) are included as a quadratic function as to allow for possible nonlinear effects.

$\mathrm{CCl}$, Charlson Comorbidity Index;; COS, Consequences in Screening; FDR, False Discovery Rate. 
design, non-response rates in the control groups in these three trials were similar, and in all three trials there was differential non-response between the intervention and control group. Differences between attenders and nonattenders were reported in the UKLS trial. As in the DLCST, non-attenders had worse sociodemographic profile that is, lower social class, and they were more likely single, younger and current smokers compared with attenders. However, these were pooled estimates for both the screening group and the control group.

In individuals diagnosed with cancer, anxiety and worse health-related quality of life have been associated with dropout, which is consistent with our findings. ${ }^{20}$ Since non-attenders in our study experienced a higher level of anxiety than attenders in the first screening round (ie, baseline), this could have been the motivation for attending the trial; to get reassured of being healthy. ${ }^{21}$ Therefore, randomisation to the control group may have caused disappointment but also attention drawn to not being part of a possibly beneficial intervention. ${ }^{22}$ For example, the secretary in the screening clinic received calls from participants randomised to the control group expressing their disappointment of not being screened. Furthermore, the trial put focus on the harms of smoking, which could have increased the anxiety and fear of disease in this subgroup even more, which may have been a reason for subsequent non-attendance. Finally, missing data on psychosocial status in a previous round may also have been a predictor for non-attendance in the next screening round, which was not the scope of this study.

Low social status, younger age and current smoking status have previously been seen among dropouts and nonrespondents in lung health studies. ${ }^{23-26}$ A systematic review reporting dropout from longitudinal studies in elderly concluded that higher age and declining health were high predictors of dropout. The latter is in agreement with our findings, although higher age is in contrast to our findings. ${ }^{27}$

To our knowledge, this is the first cancer screening study testing hypotheses on reasons for differential non-response empirically. The results of this study confirmed the hypotheses we made in our previous study, using inverse probability weighting to adjust for differential non-response. ${ }^{3} 728$ More importantly, the results of the two other lung cancer screening trials investigating dropout are consistent with ours. Hence, it is plausible that our results are generalisable to other cancer screening trials as well.

Therefore, future cancer screening trials should concurrently assess psychosocial status during the trial to be able to assess the psychosocial effect of screening and to use this information to adjust any effect in the trial for bias due to differential non-attendance.

\section{CONCLUSIONS}

In conclusion, non-attenders in the control group in the DLCST had a worse psychosocial status and a less favourable sociodemographic profile than attenders.
The results of our study contribute with evidence of non-response driven by psychosocial status, which in turn may be influenced by the screening intervention itself. This can be used to adjust cancer screening trial results for bias due to differential attendance.

\section{Author affiliations}

${ }^{1}$ The Section of General Practice and Research Unit for General Practice, Department of Public Health, University of Copenhagen, Copenhagen, Denmark ${ }^{2}$ The Primary Health Care Research Unit, Region Zealand, Copenhagen, Denmark ${ }^{3}$ Family Medicine Unit, NOVA Medical School, Universidade Nova de Lisboa, Lisbon, Portugal

\section{Twitter Bruno Heleno @bruno_m_heleno}

Acknowledgements We wish to thank data manager Willy Karlslund for his contribution to generation of the databases and statistician Christine Winther Bang for performing the log-transformed analyses. Finally, we wish to thank the DLCST steering committee.

Contributors JB and $\mathrm{HT}$ developed and designed the study. JB, $\mathrm{HT}$ and the DLCST staff collected data. VS performed the statistical analyses. JM drafted the manuscript. JB, HT, BH, JFR and VS all contributed to parts of the manuscript as well as revisions of the manuscript. All authors approved the final version of the manuscript, and no editorial assistance was received. All authors had full access to all data in the study and are responsible of data retention and the accuracy of the data analysis. JM and JB are guarantors of the study.

Funding This work was supported by the Danish Ministry of Interior and Health, grant number 0900814 . The funding source had no role in study design, data collection and analysis, decision to publish or preparation of the manuscript.

\section{Competing interests None declared.}

Patient consent for publication Not required.

Ethics approval The Ethical Committee of Copenhagen County approved the DLCST including this observational study nested in the DLCST on 31 January 2003 : approval number KA-02045. All participants signed an informed consent form and received an information letter about the project and information about the ethical approval and data protection agency approval.

Provenance and peer review Not commissioned; externally peer reviewed.

Data availability statement Data are available upon reasonable request. The corresponding author can provide the questionnaires and datasets generated and analysed during the study on reasonable request.

Open access This is an open access article distributed in accordance with the Creative Commons Attribution Non Commercial (CC BY-NC 4.0) license, which permits others to distribute, remix, adapt, build upon this work non-commercially, and license their derivative works on different terms, provided the original work is properly cited, appropriate credit is given, any changes made indicated, and the use is non-commercial. See: http://creativecommons.org/licenses/by-nc/4.0/.

\section{ORCID iDs}

Jessica Malmqvist http://orcid.org/0000-0002-9299-4369

Volkert Siersma http://orcid.org/0000-0003-1941-2681

John Brodersen http://orcid.org/0000-0001-9369-3376

\section{REFERENCES}

1 Tierney JF, Stewart LA. Investigating patient exclusion bias in metaanalysis. Int J Epidemiol 2005;34:79-87.

2 Zhang Y, Alyass A, Vanniyasingam T, et al. A systematic survey of the methods literature on the reporting quality and optimal methods of handling participants with missing outcome data for continuous outcomes in randomized controlled trials. $J$ Clin Epidemiol 2017;88:67-80.

3 Dufouil C, Brayne C, Clayton D. Analysis of longitudinal studies with death and drop-out: a case study. Stat Med 2004;23:2215-26.

4 Humphrey LL, Deffebach M, Pappas M, et al. Screening for lung cancer with low-dose computed tomography: a systematic review to update the US preventive services Task force recommendation. Ann Intern Med 2013;159:411-20. 
5 Wu GX, Raz DJ, Brown L, et al. Psychological burden associated with lung cancer screening: a systematic review. Clin Lung Cancer 2016;17:315-24.

6 Brain K, Lifford KJ, Carter B, et al. Long-Term psychosocial outcomes of low-dose CT screening: results of the UK lung cancer screening randomised controlled trial. Thorax 2016;71:996-1005.

7 Rasmussen JF, Siersma V, Pedersen JH, et al. Psychosocial consequences in the Danish randomised controlled lung cancer screening trial (DLCST). Lung Cancer 2015;87:65-72.

8 Pedersen $\mathrm{JH}$, Ashraf H, Dirksen A, et al. The Danish randomized lung cancer CT screening trial--overall design and results of the prevalence round. J Thorac Oncol 2009;4:608-14.

9 Brodersen J, Thorsen H, Kreiner S. Consequences of screening in lung cancer: development and dimensionality of a questionnaire. Value Health 2010;13:601-12.

10 Aggestrup LM, Hestbech MS, Siersma V, et al. Psychosocial consequences of allocation to lung cancer screening: a randomised controlled trial. BMJ Open 2012;2:e000663.

11 Heydarpour B, Saeidi M, Ezzati P, et al. Sociodemographic predictors in failure to complete outpatient cardiac rehabilitation. Ann Rehabil Med 2015;39:863-71.

12 de Graaf R, van Dorsselaer S, Tuithof M, et al. Sociodemographic and psychiatric predictors of attrition in a prospective psychiatric epidemiological study among the general population. result of the Netherlands mental health survey and incidence Study-2. Compr Psychiatry 2013;54:1131-9.

13 Field JK, Duffy SW, Baldwin DR, et al. Uk lung cancer RCT pilot screening trial: baseline findings from the screening arm provide evidence for the potential implementation of lung cancer screening Thorax 2016;71:161-70.

14 McCaffery KJ, Barratt AL. Assessing psychosocial/quality of life outcomes in screening: how do we do it better? J Epidemiol Community Health 2004;58:968-70.

15 Brodersen J, Thorsen $\mathrm{H}$. Consequences of screening in breast cancer (COS-BC): development of a questionnaire. Scand J Prim Health Care 2008;26:251-6.

16 Benjamini Y, Hochberg Y. Controlling the false discovery rate: a practical and powerful approach to multiple testing. Journal of the Royal Statistical Society: Series B 1995;57:289-300.
17 Brodersen J, Thorsen $\mathrm{H}$, Cockburn J. The adequacy of measurement of short and long-term consequences of false-positive screening mammography. J Med Screen 2004;11:39-44.

18 DeFrank JT, Barclay C, Sheridan S, et al. The psychological harms of screening: the evidence we have versus the evidence we need. $J$ Gen Intern Med 2015;30:242-8.

19 van den Bergh KAM, Essink-Bot ML, Borsboom GJJM, et al. Long-Term effects of lung cancer computed tomography screening on health-related quality of life: the Nelson trial. Eur Respir J 2011;38:154-61.

20 Mercieca-Bebber RL, Price MA, Bell ML, et al. Ovarian cancer study dropouts had worse health-related quality of life and psychosocial symptoms at baseline and over time. Asia Pac J Clin Oncol 2017;13:e381-8.

21 Osterø J, Siersma V, Brodersen J. Breast cancer screening implementation and reassurance. Eur J Public Health 2014;24:258-63.

22 Wendler D, Krohmal B, Emanuel EJ, et al. Why patients continue to participate in clinical research. Arch Intern Med 2008;168:1294-9.

23 Snow WM, Connett JE, Sharma S, et al. Predictors of attendance and dropout at the lung health study 11-year follow-up. Contemp Clin Trials 2007;28:25-32.

24 Nohlert E, Öhrvik J, Helgason Ásgeir R. Non-responders in a quitline evaluation are more likely to be smokers - a drop-out and long-term follow-up study of the Swedish National Tobacco Quitline. Tob Induc Dis 2016;14:5.

25 Abrahamsen R, Svendsen MV, Henneberger PK, et al. Non-Response in a cross-sectional study of respiratory health in Norway. BMJ Open 2016;6:e009912.

26 Oleske DM, Kwasny MM, Lavender SA, et al. Participation in occupational health longitudinal studies: predictors of missed visits and dropouts. Ann Epidemiol 2007;17:9-18.

27 Chatfield MD, Brayne CE, Matthews FE. A systematic literature review of attrition between waves in longitudinal studies in the elderly shows a consistent pattern of dropout between differing studies. $J$ Clin Epidemiol 2005;58:13-19.

28 Rotnitzky A, Robins J. Analysis of semi-parametric regression models with non-ignorable non-response. Stat Med 1997;16:81-102 